\title{
NOV 101989
}

\section{8

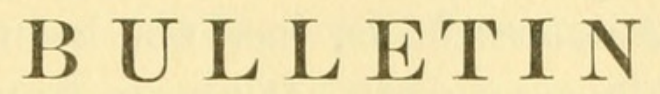

OF THE

\section{FSSFX INSTITUTH.}

Vol. 24. SAlem: April, May, June, 1892. Nos. 4, 5, 6.

\section{THE REPTILES OF THE GALAPAGOS ISLANDS.}

From the Collections of Dr. Geo. Baur.

BY S. GARMAN.

Chelonia, Sauria and Ophidia have been discovered on the Galapagos. Excluding the marine forms that may from time to time be found on the shores, only four families are represented: the Testudinidæ of the tortoises, the Iguanidæ and the Geckonidæ of the lizards, and the Colubridæ of the snakes. Neither is peculiar to the locality. The sea tortoises of the Chelonidre are known to visit the beaches, and stragglers of the Sphargidæ may also be expected to wander there. Certain of the sea snakes, Pelamis, of the Hydrophidæ, frequent the waters nearer the continent and may at times be captured among these islands.

Two genera of the lizards, Conolophus and Amblyrhynchus, are found only on the Galapagos ; their closest allies, however, are inhabitants of the western coasts of South 
America. The other five, Testudo, Tropidurus, Phyllodactylus, Gonatodes, and Orophis, are genera of which very closely allied species are distributed along the same coasts.

Only one of the species discovered on the islands, Phyllodactylus tuberculosus, has not been distinguished from those of the continent. It ranges from Chile to California. The tubercles of Dr. Baur's specimen differ so much from those of the mainland form that the type may prove to be a new variety if not a distinct species. The balance of the species, though in cases but little differentiated, are sufficiently distinct for recognition among their continental allies.

The affinities and the amount of differentiation of the species on the various islands prove beyond question that the insular genera and species were derived from those of the nearest South American coasts, either somewhat directly and recently or more remotely, from common ancestors. While there is a general agreement in regard to the sources from which the different forms of plants and animals at present inhabiting the islands were primarily derived, the agreement is not extended to the manner of derivation. Advocates of the theory of independent, volcanic, origin of the archipelago claim that accidental introductions have established the flora and fauna, and explain the varying affinities of the types by asserting the transportation of the same or of different species to particular islands and by the effects of isolation and varied surroundings. They do not consider the six hundred miles or more of distance from the source of supply to be an insurmountable obstacle, and they are favored by the great Peruvian current and by the winds. Advocates of another theory hold that the islands once were mountains connected with what is now the continent by lower lands, that by subsi- 
dence they became separated, and that the modern forms of life, with exception, perhaps, of one or a few of recent introduction, are simply the descendants of continental forms established in their present localities before the connecting lowlands disappeared in the ocean. In both theories, isolation and differences of circumstances were the important factors in differentiation; and the closeness of existing relationships may be cited in favor of each of the hypotheses.

The portion of the collection submitted to me for examination suffices for special determinations but is insufficient for purposes of generalization. It indicates that a most important contribution to the scientific history of the region might be made by one who is able to gather from each of the islands series large enough to supply the now-lacking means for comparisons. His most extensive series, that of Tropidurus, and the tortoises have already been studied by the Doctor himself. Among those identified in this paper his collection has added one genus, Gonatodes, and two new species, Gonatodes collaris and Pliyllodactylus Baurii, to the list of those reported from these localities.

One of the most interesting specimens in the collection is a small Conolophus from Barrington. It is important because of the opportunity it affords for a description of the young, and because of the light it throws on the derivation of the genus. Its resemblance to forms of Enyalioides is so great that if larger individuals were unknown we should place it in that genus by the side of $E$. laticeps, as a closely allied species. A comparison of this specimen with others of species of Enyalioides makes it very evident that Conolophus was derived from one of their immediate ancestors, the nearest, perhaps, that of E. laticeps. Conolophus and Amblyrhynchus have close anatomi- 
cal affinities, and they must have come from nearly allied forms, not from the same form. It may be that both of these genera developed on the same island, the arid belt near the shores evolving the cactus-eating Conolophus while Amblyrhynchus made its food of seaweeds. Or it may have been that Amblyrhynchus developed on one or more of the islands on which there was no alternative for the seaweed, whence the lizard has reached other localities in which it now occurs. How these saurians became possessed of the vegetarian habit is a question to which our only answer is conjecture. Its inheritance from herbivorous mesozoic progenitors that might have existed is not to be seriously considered. While it may have been the case that allied species on the mainland also to some extent fed on plants, it is more likely that scarcity of animal food rather suddenly brought upon them, whether through emigration or otherwise, compelled a change of diet. Such achange would be complete in a single generation; whereas more gradual diminution in the supply of animals might induce or permit adaptation, by reduction in size or needs, to correspond with the conditions. Conolophus with its feeding habits could only develop in such places as now harbor it, the higher of the islands, those surrounded by the cactus-bearing arid belt and possessing the fertile upper plateaus. By this fact it is restricted to a few of the islands. But Amblyrhynchus is equally at home on any of the islands with sufficient shoal water around them for the production of the seaweeds. It may have started on one of the islands that have no fertile upper belts, which are not high enough to arrest the moisture needed for vegetation. However it reached such a territory it would be obliged to depend on the beaches for subsistence, and from such a place it might spread over the entire archipelago.

The determinations Dr. Baur has reached in his studies of the genera Testudo and Tropidurus are the following: 
TESTUDO.

T. elephantopus Harl. ( $T$. vicina Gthr.) Probably James.

T. Microphyes Gthr.

Albemarle.

T. AbIngdoniI Gthr. (T. ephippium Gthr.) Abingdon.

T. galapagoensis Baur. (T. elephantopus Jack.) Charles.

T. Nigrita Dum. Bibr.

Locality unknown.

T. güntheri Baur. (T. elephantopus Gthr.) Locality unknown.

\section{TROPIDURUS.}

T. GRAYI Bell.

Charles.

T. Bivittatus Pet. (T. lemniscatus Cope.) Chatham.

T. indefatigabilis Baur. James \& Indefatigable.

T. DElanonis Baur.

Hood \& Gardner.

T. DUnCanensis Baur.

Duncan.

T. albemarlensis Baur.

Albemarle.

T. Pacificus Steind.

Abingdon.

'T. HABELII St.

Bindloe.

In connection with this genus I may add an interesting note obtained from Count L. F. de Pourtalés in a conversation after his visit to the Galapagos on the Hassler Expedition. He stated that one day as he was sitting on a rock on the shore of one of the islands he saw a hawk stoop for one of these little lizards rumning back and forth on the sands. At once on the approach of his enemy the lizard rushed into the water and remained there until the hawk had gone away. So far as I am aware no notice has heretofore been made of a disposition on the part of species of Tropidurus to enter the water.

Below are given the determinations and notes secured by a study of the remainder of the Doctor's collection.

Conolophus subcristatus Gray; St.

A specimen from Barrington has a length of body of four and three-fourths and of tail seven and one-half inches. 
It is handsomely marked and bears a striking resemblance to species of Enyalioides. This is apparent even in the gular sac and the transverse fold on the throat, and suggests that in our systems these genera are placed too far apart. The coloration differs materially from that of the large specimens. The ground color is of a light olive, lighter and uniform beneath and blotched and vermiculate on the back. Between the nape and the hips on the middle of the dorsal surface there is a series of eight lighter centred, brownish transverse bands, and between these and at their sides on the flank there are streaks forming vermiculations or rings. The rings enclose spaces of the ground color; on the lower parts of the flanks they are larger and more distinct, resembling in a measure those on the flank of Enyalioides planiceps as figured by Guichenot. The crown of the head bears scattered spots of black. The tail is brown on the top; on the middle of the side it has a more or less broken longitudinal streak of the light color, below which there is an irregular narrow band of brown separating it from the lighter color of the lower portion.

Size and color are the features in which differences are to be detected between this specimen and the larger ones. Those that obtain are such as will disappear with age. The several large individuals from the same island nearly approach a number secured by the Hassler Expedition, for the Museum Comparative Zoology, from Albemarle. The most notable of the differences between them appear in the higher labials, as compared with the length, and in a more concave frontal region on the specimens from Barrington, which probably represent a distinct variety of the species. The largest is about forty-two inches in length, half of which is tail.

Concerning the dorsal erest there are several items it may be well to notice here. In all cases the crest nearly 
or quite disappears between the hips, and on the males it attains a greater development. Each of the large spines of the neck has a small one immediately in front of it, and frequently the latter is preceded by a still smaller one. While young the spines are subpyramidal, convex on the sides and concave behind, but as they grow higher they become more subconical. Early in life the growth is rapid and steady; later it takes on a periodicity that is plainly indicated in the dorsal spines. Those on the Barrington specimens are encircled by three to six ridges, like the rings around a cow's horn. These make the outward appearance of each spine resemble that of the rattle of a small rattlesnake. In a longitudinal section, however, the layers of the epiderm are seen to lie closely against each other, not loosely as in the rattle. When with age the shape of the spine becomes subconical, a slight constriction around the base of the cap, or slough, prevents its removal. The periodic growth of the skin lengthens the spine thus pushing the older cap farther out so as to expose a portion of the base of the new one formed within it. The entire spine being dermal there is no vacant space within the successive caps, consequently, close as the external resemblance is, they do not assume the function of rattles. The appearance is brought about by the shape of the cap, or slough, and the periodicity of the growth. Though not a rattle it confirms my account of the structure and development of that organ as given in 1888 (Bull. Mus. Comp. Zool., xıIr, 259). Retention of the several caps adds to the firmmess and rigidity of the spine. On one individual the longest spines measure three quarters of an inch.

Amblyrhynchus cristatus Bell.

Dr. Baur's Collection contains specimens from Albemarle, Bindloe, Charles and Tower, and in this museum 
there are others from Albemarle, Charles, Duncan and Jervis islands. All may be placed in a single species, in which it seems possible, however, to distinguish three varieties : first, the typical form of the species, A. cristatus, with the young profusely mottled with whitish, greenish and olive and the old reddish, mottled, and clouded with darker on the sides and usually with a black blotch between the shoulders (from Albemarle, Bindloe, Charles and Jervis); second, $A$. ater, the large black form, from Duncan, which exhibits, in large specimens, little or none of the russet color or the mottling; and, third, A. nanus, a small black form from Tower island, a form that does not appear to reach half the size of that from Duncan, and which becomes nearly uniform black at a size that in $A$. cristatus has more of green and olive than brown. The smallest specimen of A. nanus is five inches in length of body and seven and one-fourth in length of tail ; the largest has a body eight inches long and a tail twelve and a half. Two specimens of $A$. ater were secured by Professor Agassiz, on the Albatross, from Duncan. The larger is fourteen inches in body and eighteen and a half in tail. The color distinguishes them at once from $A$. cristatus. Of the latter those from Charles appear to have more of the lighter colors in the young, but in the old there is little difference to be detected between the several localities. The smallest specimen, from Albemarle, measures four and a half inches in body and five and three-fourths inches in tail. It has eight or nine transverse bands, or series of lighter spots, from nape to base of tail, is mottled with lighter on flanks, and is coarsely puncticulate with brown under throat and breast. On the small ones the tubercles of the head are light colored, and spots of the same color form a sort of rosette on the nape. The tubercles of the forehead are flat or convex scales at first, later they become carinate 
and finally subconical. On the dorsum the crest is first indicated by convex scales that become compressed and ultimately subconical or pointed. In this genus the crest on the neck shows the appearance of the rattles more than that on the back, the opposite of what occurs on Conolophus.

While looking over the specimens belonging to the Museum of Comparative Zoology with Count Pourtalés, he mentioned a statement of Darwin to the effect that this species does not take to the water for safety, but that when Darwin had thrown them in they immediately returned to the shore. The Count said that, from his own observations, among large rocks where there were fishes the lizards preferred to hide in crevices on shore; but that he saw them along the open places, where there were numbers of them, run into the sea, near the beach where the water was shallow, and secrete themselves under the rocks when pursued from the land.

\section{Phyllodactylus tuberculosus Wieg.}

This identification may yet be questioned. The specimen in the collection, from Chatham, is badly mutilated. It agrees with Wiegmann's species in the distribution of the tubercles but differs in their shape and size; they are broader and flatter with the keel more distinct from the rest of the upper surface.

\section{Phyllodactylus galapagoensis Pet.}

Dr. Boulenger gives the locality of this species as Charles Island. Dr. Baur's specimens are all reported from Albemarle, where it would from his collections appear to be the only species of the genus. The largest individual measures three and three-quarters inches, indicating a smaller species than $P$. tuberculosus, of which specimens 
of my collecting in the Daule region, above Guayaquil, reach five and a half. The dorsal tubercles are less developed, and those on the head and neck are less numerous than those of that species, while the large scales below the tail are not arranged in a regular series. Of ten specimens, five have three submentals in contact with the mental, as described by Peters; four of the others have but two submentals in the same position, as stated by Boulenger; and one individual has four submentals against the mental shield. In most respects the descriptions of coloration given by the mentioned authors accords with that present on these specimens. A striking contrast is presented by one example: its ground color is light and the markings are black; between the nape and the base of the tail there are eight transverse bands, bifurcating toward the flank; on the tail there are thirteen of the black bands; and the black band from the nostril through the eye is met at the ear by that from the nape. Ordinarily the dorsal blotches are brown, separated along the vertebral line, and reduced to two series of spots.

\section{Phyllodactylus Baurit sp. n.}

This species is still farther than the preceding from $P$. tuberculosus. There are but five rows of tubercles on each side and they are smaller and more irregularly placed in the rows. The scales of the back of the head and the neck are granular, as in P. Reissii. The mental is rather short; it is broad and forms an obtuse angle posteriorly, between two large submentals. The first infralabials are about one-fourth as large as the mental, by which they are widely separated. Forward from a vertical through the pupil there are six labials and five to six infralabials.

The colors and markings are like those of $P$. galapagoensis. The reduction or absence of the tubercles on the 
neck brings this species close to $P$. Reissii, described by Peters from Guayaquil ; the latter is readily distinguished by its mental shield which is almost entirely between the first pair of infralabials, and these are hardly smaller than the mental itself.

\section{Hab. Las Cuevas, Charles Island.}

Phyllodactylus Leei Cope.

On one individual there are six labials in front of a vertical through the pupil on one side and seven on the other.

\section{Hab. Chatham Island.}

Gonatodes collaris sp. n.

Head moderate; snout obtusely pointed, longer than the distance between the eye and the ear opening, one and one-half times the diameter of the orbit, equal the width of the crown at the hinder edge of the orbit; forehead flat; ear opening small. Digits slender; basal joint slender, subcylindrical, with larger plates beneath; other joints more slender, compressed. Head, throat, upper portions of body, limbs and tail covered with subequal granular scales, smallest on the occiput, larger on chin and tail. Rostral broader than high, pentagonal, incised on the top. A small internasal toward each side. Two small shields behind the nostril. Six labials; sixth small, slightly behind the middle of the eye. Five infralabials; posterior nearly reaching a vertical from the hinder border of the eye ; first large, in contact with two submentals; mental large, with a median and two lateral angles posteriorly, in contact with a pair of moderate submentals, at each side of which there is one scarcely half as large, from which again a diminishing series of three or four passes back along the infralabials. Abdominal scales moderate, imbricate, heptagonal, flat, similar to scales in front of thighs and arms. 
Tail tapering, subround, covered with small imbricate scales above and larger ones beneath. The median row under the tail is subject to great variation : on two of the specimens the scales are about twice as broad as long; on two others they are so broad as to reach from side to side of the tail. The granules of the throat are fine, quite as small as those of the occiput; near the labials and submentals they rapidly increase in size.

Body and limbs dark brownish; back darker, with numerous small spots of light blue. A dark-edged spot of the blue above the shoulder. In front of each shoulder there is a vertical band of bluish that does not reach the median line on the top of the neck. Along the vertebral line the back is lighter, and along this light band there are five pairs of dark spots, and at the hinder edge of each of these spots there is a smaller one of the light color. The first pair of the spots lies transversely in front of the vertical band, the second behind the shoulders, the third near the middle of the body, the fourth in front of the leg, and the fifth across the base of the tail.

Chin and throat yellow to orange. Top and sides of head brown; with a yellow band from the angle of the mouth to the nape, another from the eye to the parietal region, and a third from the nostrils backward over the supraorbitals. On the crown the disposition of the yellow is irregular, but on each specimen there is a short median streak of the light color.

This form is very closely allied to Gray's species $G$. ocellatus from Tobago. The principal differences seem to be in the coloration. The vertical streak is in front of the shoulder, and to reach the latter would bave to turn back at its lower end. The head is not so high, and the outline from rostral to occiput is very slightly but quite regularly curved. In the figure given, by Dr. Boulenger, 
of $G$. ocellatus, the scales under the fourth toe are smaller toward the base; in our species they are about equal in size.

Hab. Wreck Bay, Chatham Island.

Orophis biserialis.

Herpetodryas biserialis Gthr., 1860, Pr. Zool. Soc. Lond., 97.

Dromicus Chamissonis Pet., 1869, M. B. Berl. Akad., 719 .

D. Chamissonis var. biserialis Gthr., 1870, Zool. Rec., vi, 1869, 115.

D. Chamissonis var. dorsalis and var. Habelii Steind., 1876, Schl. u. Eid. der Galap.-Inseln, p. 6, pl. 1. Opheomorphus Chamissonis Cope, 1889, Pr. U.S. Mus., 147.

There is a single specimen of this snake in the collection from Hood Island. It is intermediate between Günther's species biserialis and Steindachner's variety Habelii. Structurally it agrees with the type described by Günther, but it has no spots on the back. The dorsal band is continuous, though fainter and indistinctly margined behind the middle of the length. The type from which the species was originally described was said to be from Charles Island. The present specimen from another locality possesses the squamation of one of the so-called varieties and the coloration of the other. This seems to me to indicate the existence of but one variety, of which the spotted forms and those with three postorbitals are individual variations. There is nothing in the published evidence to show that the striped form, the spotted form, that with two postorbitals, and that with three do not occur amongst the individuals of any of the localities inhabited by this snake. 
Günther's type has three postorbitals and is spotted, Dr. Baur's specimen has three postorbitals and is striped, and Steindachner's varieties both striped and spotted have but two postorbitals.

Steindachner's specimens are from Charles, Hood, Indefatigable, and Jervis Islands, Baur's and Günther's are from Charles and Hood.

The species was first placed by Dr. Günther in Herpetodryas. Peters removed it to Dromicus. The type species of Dromicus is $C$. angulifer, with two scale pores, which differs too much to admit of including the Galapagos serpent with it in the same genus. Liophis was based by Wagler on L. miliaris or L. Merremii, and Opheomorphus thus becomes a synonym, being founded on the same type. Since Fitzinger, 1843, has applied the name Orophis directly to O. Chamissonis it would appear that the best way out of the confusion lies in retaining his generic designation for that species and others not generically distinct.

Orophis biserialis differs from O. Chamissonis mainly in having a larger number of scutes. Our specimen has 19 rows, no pores, 209 scutes under the body, a divided anal, a mutilated tail, one loreal, one anteorbital, three postorbitals, eight labials, and ten infralabials. The frontal does not widen in front; between the supraorbitals its sides are parallel. The lateral band of light color extends along the two outer rows of scales, and the upper light band is on the sixth and seventh rows. The dorsal band of brown occupies five entire rows with the adjoining edges of two others; the lateral bands of this color occupy but three rows with the adjoined edges of two more. All of the bands fade posteriorly. The lateral bands of brown begin at the nostrils and pass through the eye to the flanks; the dorsal band begins on the forehead, where it is not so dark. Anteriorly there are spots under the body; pos- 
teriorly the spots do not appear and the color is more uniform white or yellowish. The edges of the scales are darker. The greater part of the brown in the coloration is in the shape of coarse puncticulations; these are continued more or less completely across the abdomen on the hinder edges of the scutes. On its edges the dorsal band has the appearance of being serrated. Dr. Günther found 209 ventral scutes on the type specimen. Steindachner found the ventrals on his examples to vary from 219 to, 225 and the subcaudals from 105 to 114 . On O. Chamissonis the ventrals vary from 175 to 201 and the subcaudals from 100 to 113 .

Mus. Comp. Zool., Jan., 1892,

Cambridge, Mass. 


\section{$2 \mathrm{BHL}$ Biodiversity Heritage Library}

Garman, Samuel. 1892. "The reptiles of the Galapagos Islands. From the collections of Dr. Geo. Baur." Bulletin of the Essex Institute 24, 73-87. https://doi.org/10.5962/bhl.part.18576.

View This Item Online: $\underline{\text { https://www.biodiversitylibrary.org/item/33877 }}$

DOI: https://doi.org/10.5962/bhl.part.18576

Permalink: https://www.biodiversitylibrary.org/partpdf/18576

\section{Holding Institution}

Harvard University, Museum of Comparative Zoology, Ernst Mayr Library

\section{Sponsored by}

Harvard University, Museum of Comparative Zoology, Ernst Mayr Library

\section{Copyright \& Reuse}

Copyright Status: Public domain. The BHL considers that this work is no longer under copyright protection.

This document was created from content at the Biodiversity Heritage Library, the world's largest open access digital library for biodiversity literature and archives. Visit BHL at https://www.biodiversitylibrary.org. 